\title{
Ranking Political Science Departments: Do Publications Matter?*
}

\author{
James C. Garand, Lovisiana State University* \\ Kristy L. Graddy, Lovisiana State University
}

C 1995 the National Research

Council (NRC) released the re-

sults of its most recent study of the subjective evaluations of the quality and effectiveness of political science departments in the United States with Ph.D. programs. These NRC rankings of graduate programs created quite a stir in the political science profession, and generated several studies that explored the determinants of these rankings (Katz and Eagles 1996; Jackman and Siverson 1996; Lowry and Silver 1996; Miller, Tien, and Peebler 1996).

One of the most surprising findings reported in the subsequent analyses was that the scholarly productivity of political science departments was poorly related to the subjective evaluations of departmental quality. To be sure, there has long been a tension between subjective and objective criteria for evaluating the quality of political science departments. Departments with strong records of publication in leading scholarly journals and with respected scholarly presses are often not housed in universities that are the traditional powerhouses of academe. Still other departments with strong scholarly traditions often receive subjective evaluations that go beyond their relatively weaker records of scholarly productivity. In a discipline where scholarly merit is the basis for evaluation, one would ex-

James C. Garand is professor of political science at Lovisiana State University. $\mathrm{He}$ is former editor of the American Politics Quarterly, and has published numerous articles on a wide array of topics in the field of American politics.

Kristy L. Graddy received her B.A. in political science from Southern Illinois University, Carbondale in 1996, as well as the MPA from Louisiana State University in 1998. She is currently a Ph.D. student in political science at LSU where she specializes in the field of American politics. pect the research productivity of departmental faculties to be more inextricably linked to the subjective evaluations of departments' quality, subject to some delay in the effect over time. This does not always appear to be the case.

In this brief note, we reconsider the role that faculty publications play in shaping NRC evaluations. We explore the possibility that NRC ratings are affected by faculty publications, but that this effect is based primarily on publications in the highest-visibility journals of political science.

\section{Do Publications Matter?}

Katz and Eagles (1996), Jackman and Siverson (1996), and Lowry and Silver (1996) each explored the possibility that research productivity is related to NRC ratings, but in no case did these authors find that publications had a significant impact on departmental reputations. Department publications-whether measured as total publications, publications per faculty member, or the percentage of faculty publishing something from 1988 to 1992-had no significant effect on NRC quality ratings; with all else equal, according to these analyses, more productive departments were not evaluated more favorably than less productive departments.

To be sure, these authors did find strong evidence that citations of scholarly research had a strong, significant impact on NRC ratings. This suggests that it is not publications per se that affect subjective evaluations of political science departments, but rather that it is high-impact publications (i.e., those that generate citations by other scholars) that do so. Motivated departments could, presumably, improve their reputations over time by having fac- ulty members who produce highimpact publications that generate a large number of citations. These findings suggest that it is the quality of faculty publications, rather than the quantity of faculty publications, that has an impact on departments' reputations.

Part of the problem in estimating publication effects appears to stem from the way in which the NRC measured research productivity. The NRC relied on a measure of publication productivity during the years from 1988 to 1992 (inclusive), as reported by the Institute of Scientific Information. This measure gave equal weight to all publications, regardless of whether they were published in the leading journals and scholarly presses or in some of the less-visible scholarly outlets in political science (NRC 1993, app. G). Clearly, this presents a potentially significant problem. Perhaps the best way to assess the impact of publications on departmental reputations would be to have a measure that somehow incorporates the relatively clear-cut pecking order of scholarly journals, as described by Giles, Mizell, and Patterson (1989) and Garand (1990).

Fortunately, two sources of such data do exist. First, in an unpublished memo, Teske (1996) reported department-level data on the number of articles published by departmental faculty from 1986 to 1995 in the American Political Science Review, Journal of Politics, and American Journal of Political Science, which are generally recognized as the most rigorous and highly visible general journals in the political science profession. Teske reported data on the raw number of publications (weighted by coauthorship) in the three journals for the 40 departments with the highest number of publications, 36 of which were 
among those evaluated by the NRC. ${ }^{1}$ These data provide a reasonable indicator of the degree to which faculty members in a given political science department are publishing the results of their research in the profession's most rigorous, most visible journal outlets.

In order to incorporate Teske's data into our analysis, we created a per capita measure of scholarly productivity by dividing Teske's raw number of publications by the number of faculty in each department. Because Teske only reports data for 40 top-rated departments, we were faced with the prospect of omitting quite a few departments from our analysis for lack of data. Fortunately, there are several ways to correct for this lack of data. ${ }^{2}$ We decided to collapse the data into ordinal categories based on the placement of departments in Teske's ranking. We calculated the per capita measure for all 36 departments for which data were available on total publications in the top journals and the number of faculty. We then placed departments into five categories, with departments among the top ten coded 4, departments ranked $11-20$ coded 3 , those ranked 21-30 coded 2, departments ranked 31-36 coded 1, and unrated departments coded 0 . Using this approach, we captured at least some of the gradations among ranked departments and were also able to include in our analysis all of the departments that were not ranked by Teske but were ranked by the NRC.

Second, Ballard and Mitchell (1998) reported more detailed data on the publication records of Ph.D.-granting departments in political science. They developed a count of the number of publications in several leading political science journals-American Political Science Review, Journal of Politics, American Journal of Political Science, World Politics, Comparative Politics, British Journal of Political Science, Political Research Quarterly (formerly Western Political Quarterly), Polity, and Political Science Quarterly-for the years 1986 to 1996 , and then weighted this count by the relative "impact" of these journals, as defined by Garand (1990). Ballard and Mitchell created a per capitized measure of impactweighted departmental journal publications in order to account for the wide variation in the size of political science departments. Because Ballard and Mitchell included publication data on an inclusive set of journals and for 91 NRC-rated departments, their measure can be viewed as a comprehensive measure of departmental journal productivity. ${ }^{3}$

Armed with these two measures of departmental productivity, we assess the effect of publications by departmental faculty in the leading political science journals by estimating a model that includes several independent variables that reflect the usual suspects from previous research: (1) university-wide academic reputation, representing the so-called "halo effect," measured with the global measure provided by the U.S. News and World Report (1996); (2) faculty size, measured as the number of faculty, as well as the number of faculty squared; (3) full professors as a percentage of the total number of departmental faculty; (4) number of Ph.D.s granted from 1987-88 to 1991-92; (5) a dichotomous variable for universities located in southern states; (6) citations per faculty member from 1988 to 1992 , as well as the gini coefficient representing the degree to which publications are concentrated in the hands of one faculty member; (7) a gini coefficient for faculty publications; and (8) the various faculty publication variables, as described above. Some of these variables (e.g., publications, citations) represent the work product of political science departments, while others (e.g., south region, university-wide academic reputation) represent variables that are largely beyond the short-term control of a given department.

As our dependent variable, we utilize the ratings by the NRC of "scholarly quality of program faculty." This variable is based on mean responses from a sample of political scientists in which respondents were asked to rate each Ph.D. program on a scale from 0 ("not sufficient for graduate education") to 5 ("distinguished") (NRC 1993).

\section{Empirical Results}

In Table 1 we present regression estimates for three models of NRC rankings, with the models varying depending on which measure of departmental publications is utilized. In Model 1 we include the measure of publications per faculty member as reported by the NRC; in Models 2 and 3 we substitute measures of departmental productivity based on the publications data provided by Teske (1996) and Ballard and Mitchell (1998), respectively. It should be noted at the outset that the models fit the data very well, with $\mathrm{R}^{2}$ values in the 0.90 range, and the coefficients for the control variables are almost exclusively significant and in the expected direction.

The results in Model 1 are, for the most part, consistent with those reported in previous assessments of the effect of publications on NRC ratings; neither per capita publications nor the publication gini variable (representing the distribution of publications across all faculty) is related to quality ratings. Departments with more publications and with publications spread throughout the faculty are no more or less likely to receive high NRC ratings. As noted, this is a surprising finding, since research productivity is viewed by many as an important indicator of a department's overall scholarly quality.

Of course, in Model 1 the coefficients for the citations per faculty member and gini citations variables are significant and in the expected direction. The coefficient for per capita citations is positive, indicating that departments whose faculty generates cited work are more likely to have stronger NRC quality ratings than departments whose faculty produce articles that garner few citations. The negative coefficient for the gini citations variable reflects the stronger NRC ratings for departments in which citations are distributed throughout the faculty; when citations are concentrated in the hands (or vitae) of one or a few faculty members, the reputation of the department declines. Arguably, it is in the coefficients for the two cita- 
TABLE 1

Parameter Estimates for Models of National Research Council Quality Ratings

\begin{tabular}{|c|c|c|c|c|c|c|}
\hline & \multicolumn{2}{|c|}{ (1) } & \multicolumn{2}{|c|}{ (2) } & \multicolumn{2}{|c|}{ (3) } \\
\hline & $b$ & $t$ & $b$ & $t$ & $b$ & $t$ \\
\hline Intercept & -0.868 & $-2.021^{*}$ & -0.742 & $-2.238^{\star}$ & -1.152 & $-3.086^{\star}$ \\
\hline $\begin{array}{l}\text { University academic reputation } \\
\text { Number of faculty } \\
\text { Number of faculty squared }\end{array}$ & $\begin{array}{c}0.671 \\
0.059 \\
-0.0006\end{array}$ & $\begin{array}{r}9.077^{\star} \\
3.327^{\star} \\
-2.268^{\star}\end{array}$ & $\begin{array}{c}0.633 \\
0.044 \\
-0.0003\end{array}$ & $\begin{array}{r}10.118^{\star} \\
2.354^{\star} \\
-1.180\end{array}$ & $\begin{array}{c}0.681 \\
0.059 \\
-0.0006\end{array}$ & $\begin{array}{r}10.564^{*} \\
3.350^{\star} \\
-2.168^{\star}\end{array}$ \\
\hline $\begin{array}{l}\text { Percentage full professors } \\
\text { Number of Ph.D.s granted } \\
\text { South region }\end{array}$ & $\begin{array}{r}0.008 \\
0.004 \\
-0.161\end{array}$ & $\begin{array}{r}2.801^{\star} \\
1.784^{\star} \\
-1.935^{\star}\end{array}$ & $\begin{array}{r}0.011 \\
0.005 \\
-0.245\end{array}$ & $\begin{array}{r}4.050^{\star} \\
2.364^{*} \\
-3.546^{\star}\end{array}$ & $\begin{array}{r}0.009 \\
0.005 \\
-0.185\end{array}$ & $\begin{array}{r}3.323^{\star} \\
2.021^{*} \\
-2.322^{\star}\end{array}$ \\
\hline $\begin{array}{l}\text { Citations per faculty member } \\
\text { Gini index of faculty citations }\end{array}$ & $\begin{array}{r}0.076 \\
-0.006\end{array}$ & $\begin{array}{r}3.503^{\star} \\
-3.100^{\star}\end{array}$ & $\begin{array}{r}0.047 \\
-0.005\end{array}$ & $\begin{array}{r}4.071^{\star} \\
-3.246^{\star}\end{array}$ & $\begin{array}{r}0.052 \\
-0.004\end{array}$ & $\begin{array}{r}4.279^{*} \\
-2.546^{*}\end{array}$ \\
\hline $\begin{array}{l}\text { NRC publications per faculty member } \\
\text { Teske publications per faculty member } \\
\text { Ballard/Mitchell publications per faculty } \\
\text { member }\end{array}$ & $\frac{0.043}{-}$ & $\begin{array}{c}0.384 \\
-\end{array}$ & $\begin{array}{c}-\overline{147} \\
- \\
-0.0002\end{array}$ & $\overline{6.076}^{*}$ & $\overline{-}$ & $\overline{-}$ \\
\hline Gini index of faculty publications & 0.0001 & 0.077 & -0.0002 & -0.136 & 0.001 & 0.487 \\
\hline $\begin{array}{l}N \\
\mathrm{R}^{2} \\
\mathrm{~F}\end{array}$ & $\begin{array}{r}95 \\
0 \\
159\end{array}$ & & 215 & & $\begin{array}{r}9 \\
14\end{array}$ & \\
\hline
\end{tabular}

Note: All t statistics are calculated based on heteroskedastic robust standard errors.

${ }^{*} P<.05$, one-tailed test

tions variables that the true effect of publications can be discerned. The null coefficients for publications suggest that "mere" publications do not determine departmental reputations; rather, reputations for quality follow from high-impact publications that generate a considerable number of citations by other scholars.

Although this interpretation is certainly plausible, it begs the question of whether the measure of publications used by the NRC is the most appropriate one to use. In Models 2 and 3 of Table 1 we explore the effects of publications in high-visibility journals, as defined by Garand (1990) and measured by Teske (1996) and Ballard and Mitchell (1998). These results paint a very different portrait of the effect that research productivity has on NRC quality ratings. While publications in general proved to be virtually unrelated to NRC quality assessments of political science departments in Model 1, Models 2 and 3 show that a record of publications in high-impact journals has a very strong effect on scholarly reputations. In Model 2, we explore how per capita publications in the $A P S R$, $A J P S$, and $J O P$ affect NRC ratings; the results suggest that a one-unit increase in the five-point ordinal scale representing the number of publications in these journals increases NRC ratings by about oneseventh of a point $(b=0.147, t=$ $6.076, p<0.0001$ ). Controlling for the effects of other variables in the model, this represents a predicted difference in NRC ratings of 0.588 (i.e., $4 * 0.147$ ) for departments among the top 10 in productivity (i.e., those for which $Y_{i}=4$ ) and departments not included among the top 36 (i.e., those with $Y_{i}=0$ ). The results are similar for Model 3, in which we consider the impact of weighted per capita publications in nine high-impact journals, as reported by Ballard and Mitchell (1998). The coefficient for weighted per capita publications is both positive and highly significant $(b=$ $0.025, \mathrm{t}=3.763, p<0.0001)$. This observed effect is particularly noteworthy, since the research productivity measure is based on publications in a wide range of highly regarded political science journals.

\section{Discussion and Conclusion}

Clearly, these results provide substantial evidence that publications do matter in the subjective evaluations of political science departments. The key to finding such a relationship lies in using a measure of research productivity that accounts for the stratification of publication outlets represented in the research record of a given department's faculty. Those departments whose faculty publish a great deal in relatively undistinguished scholarly outlets do not necessarily generate higher NRC ratings; merely producing many low-impact publications appears to do little to enhance a department's reputation. On the other hand, those departments whose faculty publish in the highestimpact political science journals have considerably stronger subjective reputations among fellow political scientists. Interestingly, the significant coefficient for the publication measures in Models 2 and 3 also indicates that publications in these leading journals have an independent impact on NRC ratings, regard- 
less of whether or not they generate a large number of citations. It would appear that political science departments interested in improving their reputational standing can experience some improvement by following a high-impact publication strategy.

It is also worth noting that the coefficients for the two citations variables remain significant in Models 2 and 3, suggesting that citations have an effect on NRC ratings that is independent of the effects of pub- lications in high-impact journals. However, in comparison to the results from Model 1, there is some attenuation in the magnitude of the citations coefficients in the two models that include the impact-based measures of research productivity. Once one accounts for the impact of journals represented in a department's record of research productivity, the citations variable has a diminished, though significant, impact on NRC ratings. The continued sig- nificance of the per capita citations variable is no doubt due to the fact that the impact-based measures used in Models 2 and 3 do not take into account the full range of publications that are likely to generate citations, including books published by highly regarded scholarly presses and articles published in other highly regarded journals, especially those outside of political science.

\section{Notes}

${ }^{*}$ We would like to thank Paul Teske, Neil Mitchell, Michael Ballard, Robert Lowry, Brian Silver, and Charles Tien for providing some of the data used in this study. We remain responsible for any conclusions drawn from this analysis.

1. Teske ranked 40 departments, but four of these are eliminated in this study due to lack of data. Texas A\&M University (1st), California Institute of Technology (27th), and Carnegie-Mellon University (36th) all ranked among the top 40 departments in terms of the raw number of publications in the three leading political science journals but were not rated by the NRC. Marquette University ranked 37th on Teske's list but does not have a Ph.D. program and, hence, was unrated by the NRC.

2. One solution would be to exclude these departments from the analysis; however, this would reduce the number of cases considerably, which would make it difficult to obtain dependable estimates of publication effects and the effects of other variables in our models. Moreover, eliminating those institutions whose number of publications measures fell below a given threshold would truncate the variance on this key indepen- dent variable, which could wreak havoc with estimates of publication effects. Alternatively, one could assign to the missing cases a value that would place them below the bottom-ranked departments on Teske's list, but would nonetheless permit these cases to remain in the analysis. The problem with doing this is that the assignment of a value for these cases would necessarily be arbitrary

3. Ballard and Mitchell (1998) report data for only the 50 leading political science departments; we are indebted to these authors for providing us with their full data set.

\section{References}

Ballard, Michael J., and Neil J. Mitchell. 1998. "The Good, the Better, and the Best in Political Science." PS: Political Science and Politics 31(December): 826-28.

Garand, James C. 1990. "An Alternative Interpretation of Recent Political Science Journal Evaluations." PS: Political Science and Politics 23(September): 448-51.

Giles, Michael, Francie Mizell, and David Patterson. 1989. "Political Scientists' Journal Evaluations Revisited." PS: Political Science and Politics 22(September): 613 17.

Jackman, Robert, and Randolph M. Siverson. 1996 "Rating the Ratings: An Analysis of the National Research Council's Appraisal of Political Science Ph.D. Programs." PS: Political Science and Politics 29(June): $155-60$.

Katz, Richard, and Munroe Eagles. 1996 "Ranking Political Science Programs: A View from the Lower Half." PS: Political Science and Politics 29(June): 149-54.

Lowry, Robert, and Brian Silver. 1996 "A Rising Tide Lifts All Boats: Political Science Department Reputation and the Reputation of the University." PS: Political Science and Politics 29(June): 16167.

Miller, Arthur, Charles Tien, and Andrew Peebler. 1996. "Department Rankings: An Alternative Approach." PS: Political
Science and Politics 29(December): 704 17.

National Research Council (NRC). 1993. Research Doctorate Programs in the United States: Continuity and Change. Washington, DC: National Academy Press.

Teske, Paul. 1996. "Rankings of Political Science Departments Based on Publications in the APSR, JOP, and AJPS, 1986-1995." State University of New York, Stony Brook. Manuscript.

"U.S. News and World Report Ranking of Graduate Political Science Departments." 1996. PS: Political Science and Politics 29(June): 148. 